\title{
Um Olhar Sobre Partilha Sensível nas Artes Cênicas
}

\author{
Jeferson de Oliveira Cabral \\ Universidade Federal do Rio Grande do Sul - UFRGS, Porto Alegre/RS, Brasil \\ E-mail: grandeje@gmail.com \\ Vera Lúcia Bertoni dos Santos \\ Universidade Federal do Rio Grande do Sul - UFRGS, Porto Alegre/RS, Brasil \\ E-mail: bertonica@gmail.com
}

\section{Resumo}

Este ensaio trata das relações entre as artes cênicas, mais especificamente do teatro e da dança com a fisosofia, com ênfase na partilha de conhecimento sensível. Os argumentos, aqui dissertados, intentam traçar noções de construção de conhecimento de sujeitos a partir do contato com processos formativos em teatro. Para isto, serão utilizadas noções sobre partilha, sensibilidade, estética, dentre outras; ambos aspectos encontrados nos estudos de Jacques Rancière (2005), filósofo com pensamentos voltados à educação e arte. Como procedimentos metodológicos para confecção desse texto, foram realizadas leituras do livro "Partilha do sensível", uma resenha crítica do mesmo, e por fim, a criação de diálogos entre seus argumentos e escritos de autores da pedagogia do teatro e da dança. A reflexão procura evidenciar a arte como movimento do sujeito perante si e o mundo. Deste modo, o artigo problematiza noções do texto de Rancière, trazendo suas citações e minhas próprias reflexões a respeito dos escritos, que relacionam os preceitos do autor diretamente com processos formativos nas artes cênicas.
This essay deals with the relationships between the performing arts, more specifically theater and dance with educational language, with an emphasis on the sharing of sensitive knowledge. The arguments, here discussed, try to draw notions of knowledge construction of subjects from the contact with formative processes in performing arts. For this, it will be used notions about sharing, sensitivity, aesthetics, among others; both aspects found in the studies of Jacques Rancière (2005), philosopher with thoughts focused on education and art. As methodological procedures for making this text, readings of the Rancière's book were carried out, a critical review of it, and finally, the creation of dialogues between its arguments and writings of authors of theater and dance pedagogy. Reflection seeks to show art as the movement of the subject before oneself and the world. In this way, the abstract problematizes notions of the text of Rancière, bringing his quotations and my own reflections on the writings, that relate the author's precepts directly with formative processes. 
que seria a partilha do sensível em Jacques Rancière?

Para adentrar no universo político-estético de Rancière é preciso ter em mente o cerne de suas questões, considerando a quem e a que seu discurso é destinado. Suas palavras buscam teorizar um mundo possível baseado no acesso irrestrito ao saber. Essa busca pode parecer puramente utópica, porém devemos considerar que a utopia que vislumbra um ambiente socialmente mais saudável para todos está atrelada à visão de uma educação sensível.

Deste modo, o ensaio se desenvolverá através da problematização de noções encontradas no escrito de Rancière. Trarei suas citações e compartilharei minhas próprias reflexões a respeito, que relacionam os preceitos do autor diretamente com as vertentes artísticas da dança e do teatro, na segunda metade do ensaio.

Para Rancière, partilha é tudo aquilo que podemos compartilhar infinitas vezes. Refere-se a algo que é produzido e distribuído pelo indivíduo, sendo uma ação individual que alcança o comum ao ser posto em difusão dentro da sociedade. Portanto, nas palavras do autor, a partilha está intimamente ligada às noções de sociedade, política e ética, premissas necessárias e constituintes de partilha. Todavia, Rancière reformula e dá voz a uma concepção de partilha que não é somente a material (a partilha de espaços públicos, de objetos, dentre outros), mas sim a uma atmosfera relacional mais profunda, chamada pelo teórico de partilha do sensível.

Uma partilha do sensível fixa, portanto, ao mesmo tempo, um comum partilhado e partes exclusivas. Essa repartição das partes e dos lugares se funda numa partilha de espaços, tempos e tipos de atividades que determina propriamente a maneira como um comum se presta à participação e como uns e outros tomam parte nessa partilha. (RANCIĖRE, 2005, p. 15, grifo do autor).

A partilha sensível em questão soa como um poder a ser exercido no espaço social e ofer- tado a todos os cidadãos. Essa partilha é dada como algo que acontece de maneira comunitária, em um local de entrecruzamentos de saberes, em que todos os sujeitos os constroem e os partilham. Entretanto, a eficácia da ideia é passível de discussão a partir das imperfeições éticas de qualquer sociedade. Falhas que são geridas pelos modos de organização política de tais meios.

Rancière (2005, p.16) cria em seu texto uma analogia para explicar o acesso aos bens culturais na Grécia antiga. Por meio do contato com textos de Platão, Rancière nos relata que os artesãos não tinham liberdade - ou tempo - para usufruírem de outros elementos sociais que não seu ofício: fornecer mão de obra à polis, o que a eles constituía-se como o ideal de sua participação no andamento da sociedade. Pode-se diretamente transpor a realidade milenar, exposta por Platão, aos dias atuais, pois cada vez menos velada, uma sociedade burguesa quer que os trabalhadores reconheçam seu lugar e não pensem em outras coisas a não ser na produção de força de trabalho a um governo que diz: "não pense em crise, trabalhe!"; ou outro, que o presidente clama raivosa e irresponsavelmente pela flexibilização total das atividades econômicas em meio uma pandemia, na qual o Brasil soma milhares de vítimas fatais ${ }^{1}$. Através da reflexão de Rancière sobre o que escrevera Platão, provoco um pensar: qual ser humano conseguirá emancipação intelectual e cultural, sendo que the é tolhido o direito à pausa e a um respiro poético, ou nas palavras de Rancière, sensível no cotidiano? Enquanto os que têm muito capital econômico não conseguirem ver a ascensão de uma classe menos favorecida ganhar o que por direito e luta lhe pertence, caminharemos rumo à dominância de uma elite revoltosa. Dessa forma, a noção de partilha do sensível nos:

[...] faz ver quem pode tomar parte no comum em função daquilo que faz, do tempo e do espaço em que essa atividade se

1 No dia 28 de julho de 2020, são 87.618 óbitos acumulados devido à COVID-19, conforme o site do Ministério da Saúde do Brasil (2020). 
exerce. Assim, ter aquela "ocupação" define competências ou incompetências para o comum. Define o fato de ser ou não visível num espaço comum. (Ibidem, p.16).

Tornar-se visível, para Rancière, pode ser compreendido como a possibilidade do cidadão ter acesso ao sensível, ao que não é somente material: a arte, a reflexão sobre a política e principalmente sobre sua própria existência, fator que liga seus escritos à noção de estética.

A estética pode ser entendida como o reconhecimento por meio do intelecto daquilo que possuiu o caráter de belo. Bem como, as ferramentas do sujeito para pensar sua ligação com o espaço em que vive e a forma com que se sociabiliza com o belo da vida. Logo, a relação com a arte está presente de forma categórica nos escritos de Rancière. "As práticas artísticas são "maneiras de fazer" que intervêm na distribuição geral das maneiras de fazer e nas suas relações com maneiras de ser e formas de visibilidade" (RANCIÈRE, 2005, p. 17).

Portanto, a esta reflexão é caro o entendimento da estética como uma ferramenta de emancipação do sujeito perante os jogos de saber e poder vigentes em seu cotidiano. Para Rancière a educação estética do cidadão é um caminho para ultrapassar tais problemáticas. "É esse modo específico de habitação do mundo sensível que deve ser desenvolvido pela "educação estética" para formar homens capazes de viver numa comunidade política livre" (Ibidem, p. 39). Para isso, o autor leva seu leitor a compreender questões ligadas à estética no período moderno e traz o pensador Frederich Schiller como seu aporte teórico, segundo o qual uma educação estética do indivíduo deveria ser focada em compreender que

[...] a natureza humana é "mista", ou seja, que é dotada não apenas de razão, mas de razão e sensibilidade. Sendo assim, permanecerá sempre uma empresa inútil a de elevar moralmente - isto é, racionalmente - o homem sem, ao mesmo tempo, cultivar sua sensibilidade. (SCHILLER, 1995, p. 16).
Rancière apoia-se nos escritos de Schiller para transcender a ideia de equilíbrio entre razão e sensibilidade ao escrever sobre a consciência da partilha de sensibilidade. $O$ transcender de Rancière aparece quando o autor coloca que o espaço social é o meio de construção comum da troca de saberes. Algo que para Schiller, por meio de inferências, está ligado a educação e para Rancière acontece por ela, mas também em outros campos, onde se insere a arte.

A arte, no livro "A partilha do sensível", está representada pelas vertentes da pintura, da palavra escrita, literária e do que, para o filósofo, ganha o nome de artes vivas, contemplando as artes performativas, dentro das quais o teatro está inserido.

Por que a arte possui relevância nos estudos de Rancière? Trago esse questionamento, pois nele vislumbro relações entre o poder e o saber, ou seja, poder tomar consciência da epistemologia dos variados conhecimentos de nossa sociedade, na qual seus habitantes poderiam lograr modos distintos de subjetivação ou poder ter espaço para tais reflexões e experiências, como é o caso do fazer artístico.

[...] a prática artística não é a exterioridade do trabalho, mas sua forma de visibilidade deslocada. A partilha democrática do sensível faz do trabalhador um ser duplo. Ela tira o artesão do "seu" lugar, o espaço das discussões públicas e na identidade do cidadão deliberante. (RANCIĖRE, 2005, p.65).

Com isso, a arte é para o autor como a entrada em um processo de conhecimento expandido de si mesmo, que não vê o sujeito somente através da sua identidade laboral e da sua forma de criação de capital para o mercado. Essa ideia descontrói a visão trazida anteriormente sobre o artesão grego que não podia pousar o olhar em outros campos, a não ser o campo de trabalho, assim como ressignifica o espaço da arte nessa abertura de mundos que se liga à noção de produção da sensibilidade. Rancière (2015), ao falar que a arte coloca o trabaIhador em uma posição múltipla - em que se pode trabalhar e ao mesmo tempo partilhar do espaço de decisões políticas ou até mesmo consumir arte 
- relaciona a emancipação cultural e intelectual a um poder de praticar a estética da sua existência.

O autor aponta minúcias de sua compreensão sobre o fazer artístico no que diz respeito ao seu processo de produção. Rancière aborda a produção em arte como conhecimento em si, ou seja, os saberes que constituem a obra artística são anteriores ao produto final e que há outros níveis de sensibilidade além da expectação, ao contemplar artefatos artísticos, como uma pintura, uma coreografia ou cena teatral.

Produzir une ao ato de fabricar e o de tornar visível, define uma nova relação entre o fazer e o ver. A arte antecipa o trabalho porque ela realiza o princípio dele: a transformação da matéria sensível em apresentação a si da comunidade. (RANCIĖRE, 2005, p. 67).

O produzir, então, revela uma partilha do sensível ligada ao que acontece no convívio das pessoas que se propõem a esse trabalho. Esse convívio é carregado de saberes que compõem e revelam ao sujeito em ação a possibilidade de construir com seu corpo elementos que contrapõem a ideia de que a arte não pode ser para todos. É nesse sentido que Rancière coloca o fazer artístico ligado à produção de emancipação. Nesse caso, o artista representa aquele que pode ocupar dois espaços de conhecimento: o de receptor de saberes externos que constituem o sujeito, assim como o de produtor de conhecimento sensível.

A partir dos pressupostos aqui dissertados, pode-se dizer que as artes e seus processos de feitura, provocam a conscientização de seus meios de produção aos indivíduos e tais fazeres tomam outras proporções quando postos em cena, em galerias e nas ruas. A exposição é a partilha do sensível para Rancière, sua tese é que a arte deveria soar: "[...] como transformação do pensamento em experiência sensível da comunidade" (Ibidem, p. 67). Assim, o experienciar arte é adentrar em um universo sensível que ainda hoje é pouco explorado na sociedade.

$O$ escrito de Rancière nos proporciona refletir sobre a quem é dado o poder de estetização de sua existência, de ser "dono" de suas escolhas e de ter acesso à arte. Com isso, é plausível pensar que Rancière traz em seu discurso formas poéticas e políticas de tratar o acesso a distintos saberes. Em suma, acredito que "A partilha do sensível" corresponde à possibilidade do sujeito ter os caminhos abertos aos bens materiais e imateriais presentes na sociedade.

\section{A partilha sensível de/em processos formativos em artes cênicas}

A partir deste ponto, faz-se necessário esclarecer que, a fim de que seja estabelecido um foco mais específico ao tema, a partilha do sensível será entendida como transformações possíveis ao sujeito em contato com processos de formação em dança ou teatro.

Os processos formativos em Artes Cênicas são constituídos de ações pedagógicas organizadas para distribuição de saberes pertencentes ao campo da cena artística. A palavra formação está conectada à ação do docente em partilhar sua forma didática de compreender determinado fazer artístico, na questão de produção (composição coreográfica, cena teatral, etc.). Bem como, o acontecimento que se dá quando pessoas disponibilizam-se a experienciar processos de construção de saberes em determinada área, em espaços educacionais formais e informais.

Desse modo, a partilha do sensível caracteriza-se como a possibilidade de transformação a partir de uma experiência pedagógica. A transformação referida não possui ligações com pensamentos utópicos ou místicos ligados à transcendência do estado de espírito do sujeito, mas sim em sua mudança real, visível na construção social que se desprende de suas prerrogativas individuais para deixar-se contaminar pelo outro de forma sensível, ou seja, não praticadas convencionalmente no dia-a-dia.

Num modelo de sociedade cada vez mais individualista, no qual se valoriza o acúmulo de informações em detrimento do conhecimento advindo da experiência, é preciso saber reconhecer as mais diferentes manifestações da teatralidade presentes na cultura e distinguir os seus fazeres, de modo a incentivar a construção de novas 
narrativas sobre o mundo e a ampliar as possibilidades de reconhecimento entre os seres humanos. (SANTOS, 2012, p. 116).

$\mathrm{Na}$ citação da pesquisadora em pedagogia do teatro Vera Lúcia Bertoni dos Santos, percebe-se a ligação com os preceitos de Rancière. Ambos colocam os meios de produção, Santos no teatro e Rancière em uma produção artística mais genérica, como dispositivos de abertura de portas para compreensão do mundo social de forma reflexiva e ampla.

A constituição de um espaço artístico onde processos de construções de novas narrativas sobre quem se é está ligada à partilha do sensível e à construção de um conhecimento. Esse tipo de saber é um conhecimento sensível pois, inspirado em Rancière, acredito que existe a possibilidade de produzir novas compreensões de existência através da arte.

As vertentes artísticas da dança contemporânea e das práticas teatrais, em seus desdobramentos pedagógicos, abarcam os preceitos artísticos levantados por Rancière (2005), já problematizados anteriormente, acerca de uma nova formação do sensível em um espaço de aprendizagem, contribuindo ao entendimento dos processos de formação como modo sensível de construção de conhecimento.

A dança contemporânea, em suas formulações teórica e prática, contém noções que buscam ultrapassar discussões sobre o corpo dançante. A história da dança, referida aqui por uma simples e limitada linha do tempo, até à sua constituição na contemporaneidade, primou por um específico tipo de corpo e por formulações rígidas de passos, sequências e espetáculos em cena. Porém, a dança contemporânea rompeu com os preceitos vigentes, como é o caso do corpo. O pesquisador Odailso Berté diz na dança contemporânea: "[...] o que o corpo faz em cena não remete diretamente aos exercícios físicos e às práticas de movimento através dos quais desenvolve suas habilidades, como é o caso do balé clássico, por exemplo" (BERTÉ, 2015, p. 134). Sendo assim, a ideia que carrega consigo o corpo contemporâneo já constrói uma ruptura sensível e a possibilidade de uma nova partilha e construção de novos saberes no campo da dança.

Explicitando os fatos dissertados sobre corporeidade na dança, trago meu corpo como exemplo. Disponível ao jogo lúdico, porém acima do peso ideal para um bailarino clássico ou de dança moderna, tal desconformidade com as vertentes da dança foram por mim sentidas quando adolescente. Todavia, já adulto, encontrei laços sensíveis de ligação com a dança contemporânea que possibilitaram ver-me como um bailarino e até mesmo coreógrafo de um solo que caracterizo ser um experimento em dança-teatro.

Diversas foram minhas questões. Algumas iam contra ao experimentar, pois pensava não estar apto a tratar, a utilizar o legado de Bausch como inspiração artística. Sim, por medo. Medo de não conseguir algo significativo, ou por não ter as qualidades ideais de um bailarino, mas se a própria Pina Bausch acreditava em uma dança para todos, transformei esse desassossego em força para estimular a criação de um solo. (CABRAL, 2016, p. 293).

$\mathrm{Na}$ citação anterior, materializa-se o entendimento dos fazeres da dança contemporânea com a lógica sensível de partilha de Rancière. Isso porque, ao expor a emancipação de um sujeito ao se permitir ser produtor de algo que lhe era alheio, é apresentada uma expansão de horizontes realizada através de um processo formativo em dança. Dessa forma, é plausível pensar que a transposição do ato de produzir em Artes Cênicas para concepções pedagógicas e para espaços de construção de conhecimento nas artes da cena, relaciona-se intimamente com a premissa de educação sensível. Ao ultrapassar a compreensão de que bailarinos são somente aqueles que ocupam os palcos, partilha-se uma ideia de acessibilidade ao mover-se. Isso já pode caracterizar uma dança, pois essa não precisa estar ligada aos cânones do balé clássico e permite que as pessoas possam experimentar arte sem a necessidade de encaminharem suas vidas profissionais e laborais para tais áreas.

Da mesma forma, as práticas teatrais também carregam consigo evidências de produção de conhe- 
cimento sensível. Conforme os estudos de pedagogia do teatro inferem, o jogo é uma das mais importantes noções para construção de conhecimento no teatro, pois coloca o aluno/jogador em um estado de criação de universos ficcionais. Para Santos o jogo dramático:

Trata-se de uma metodologia teatral fundamentada na improvisação teatral, que não se subordina ao texto literário, não privilegia a apresentação de um produto e tampouco se destina a formar atores virtuosos; pelo contrário, prima pela valorização do processo de trabalho como um todo. (SANTOS, 2012, p. 22).

A visão da autora reforça a ideia de partilha de saberes que correspondem ao universo cênico formal transposto aos saberes construídos durante o processo de trabalho dentro do espaço escolar. Essa transposição instrumentaliza e dá novas formas para o aluno construir sua concepção do estar em cena, como em um laboratório de aprendizagem onde o erro é permitido e onde não há pressão por criar algo diretamente para ser teatro em seu sentido mais clássico, mas sim produzir algo que o possibilita compreender o valor do processo de aprendizagem no âmbito das aulas de teatro.

No mesmo viés está o pensamento de João Pedro Alcantara Gil (2013), também pesquisador de pedagogia em teatro, que acrescenta proposições sobre a produção de conhecimento no campo teatral ainda exaltando a importância do jogo. $\mathrm{O}$ autor compreende o jogo "como criação de situação imaginária" (Ibidem, p. 3). Com isso, vislumbro uniões entre o teatro e a possibilidade do sujeito de transpor-se para outras realidades, ocupando espaços distintos de seu modo cotidiano. Tal pensamento dialoga novamente com Rancière ao falar que a arte pode levar o cidadão a uma nova visão de partilha dentro da comunidade em que vive. Ainda segundo Gil (2013, p. 4), esse procedimento teatral revela "relações possíveis do jogo com conhecimentos transformadores, com o propósito de construir uma prática pedagógica emancipadora". O teatro, em sua prática pedagógica, é efervescente no que diz respeito a provocações de mover o sujeito a partilhar novas visões de si mesmo, constituindo assim, um novo espaço de existência, mais engajada e sensível.

\begin{abstract}
A construção de conhecimento no teatro está ligada ao "compromisso com a promoção da experiência teatral (fazer e fruir, agir e refletir) de qualidade - instância privilegiada de interação de crianças e jovens com os aspectos lúdicos, estéticos e éticos do teatro, capaz de propiciar a ampliação das suas concepções sobre o mundo e a conscientização das possibilidades transformadoras de suas ações. (SANTOS, 2012, p. 25).
\end{abstract}

Em suma, o presente texto representa a potencialidade da partilha sensível em processos formativos em artes cênicas. A ideia de formação pode ser considerada como fruto da partilha de sensibilidades artísticas e a relação entre professores e alunos pode ser a arena desse acontecimento. Situação materializada por meio dos disparadores pedagógicos da dança e do teatro, que propiciam a formação das pessoas quando instigadas à experimentação de didáticas de ensino nessas vertentes artísticas; tais como a noção de jogo no teatro e a existência de corpos diversos na dança contemporanêa, aspectos já apontados aqui. Assim, é possível compreender que um professor seja o artista e as sensibilidades sejam suas estratégias de ensino, diariamente (com)partilhadas em ambientes de docência. Com esse intuito, recorri aos escritos de Rancière pela força de suas palavras e por sua forma poética de condução de ideais, que me fazem acreditar no poder da arte em abrir portas e modificar, mesmo que em fagulhas, a realidade de outras pessoas. Ademais, sinto que os autores do campo da pedagogia da dança e do teatro, nesses escritos citados, reforçam a crença de que a arte é um movimento emancipatório do sujeito perante si e o mundo. 


\section{Referências}

BERTÉ, Odailso. Dança Contempop: corpos, afetos e imagens (mo) vendo-se. Santa Maria: UFSM, 2015.

BRASIL. Ministério da Saúde, 2020. Disponível em: https://coronavirus.saude.gov.brl. Acesso em: 28 jul. 2020.

CABRAL, Jeferson. A autonomia como princípio criativo: um olhar para o processo de ensino do Grupo Experimental de Dança. In: DANTAS, Mônica Fagundes; FERRAZ, Wagner;

TOMAZZONI, Airton. (Org.). Escritos da Dança 1: olhares da dança em Porto Alegre. Porto Alegre: Canto - Cultura e Arte, 2016.

GIL, João Pedro Alcantara. Da educação artística ao ensino do teatro: contribuição para crítica à cultura escolar. Revista: Teatro: criação e construção de conhecimento, v.1, n.1, Palmas, jul./dez. 2013.

RANCIÈRE, Jacques. A partilha do sensível: estética e política. São Paulo: 34, 2005.

SANTOS, Vera Lúcia Bertoni dos. Shakespeare Enfarinhado: estudos sobre teatro, jogo e aprendizagem. Col. Pedagogia do Teatro. São Paulo: Hucitec, 2012.

SCHILLER, Frederich. A educação estética do homem. São Paulo :lluminuras, 1995.
Este é um artigo de acesso aberto distribuído sob os termos de uma Licença Crea- tive Commons Atribuição 4.0 Internacional. Disponível em: <http://creative commons.org/licenses/by/4.0>.

This is an open-access article distributed under the terms of the Creative Commons Attribution License 4.0 International. Available at: $<$ http://creative commons.org/licenses/by/4.0>.

Ce texte en libre accès est placé sous licence Creative Commons Attribution 4.0 International. Disponible sur: <http://creativecommons.org/licenses/by/4.0>.

Recebido: $16 / 04 / 2020$

Aceito: $31 / 07 / 2020$

Aprovado para publicação: 17/11/2020 